\title{
Precise characterization of outermost surface of crystalline-crystalline diblock copolymer thin films using synchrotron radiation soft $X$-ray photoelectron spectroscopy
}

Polymer Journal (2014) 46, 637-640; doi:10.1038/pj.2014.51; published online 2 July 2014

\section{INTRODUCTION}

For many nanoscience and engineering applications, the surface chemical composition of polymers dictates a material's character. Conducting a spatially resolved chemical analysis of polymer thin film surfaces is therefore of great interest. Angle-resolved X-ray photoelectron spectroscopy has been used extensively to obtain depth profiles of the chemical composition near the polymer surface. The analytical depth depends on the photoelectron take-off angle with respect to the thin film surface, and the photoelectron take-off angle must be very low for an outermost surface analysis. However, it is difficult to limit measurements to the outermost surface due to the elastic electron scattering effects, the surface roughness and the finite acceptance angle of the spectrometer lens. ${ }^{1}$ Moreover, surface roughness substantially reduces the total photoelectron intensity due to X-ray or electron shading, and X-ray reflection considerably reduces photoelectron intensity at all wavelengths. ${ }^{2}$ Synchrotron radiation (SR) soft X-ray XPS has the potential to overcome these problems. A low take-off angle setup is unnecessary for depth analysis because the inelastic mean free path of photoelectrons is very short in the case of a $400 \mathrm{eV}$ soft X-ray source.

Here, we investigate the composition gradient at the surface using thin films prepared from diblock copolymers composed of hydrophilic poly(ethylene glycol) (PEG) and hydrophobic poly(perfluorooctylethyl acrylate) $\left(\mathrm{PFA}-\mathrm{C}_{8}\right)$. The $\mathrm{PFA}-\mathrm{C}_{8}$ has perfluorooctyl side chains $\left(R_{\mathrm{f}}\right)$ that align perpendicular to the thin film surface and form a bilayer lamellar structure. ${ }^{3,4}$ The $\mathrm{PFA}-\mathrm{C}_{8}$ has various $\mathrm{C}_{1 \mathrm{~s}}$ signatures $\left(-\mathrm{CF}_{3},-\mathrm{CF}_{2}-, \mathrm{C}=\mathrm{O}, \mathrm{C}-\mathrm{O}\right.$ and hydrocarbon groups) that are observed in a wide binding energy range. Angleresolved X-ray photoelectron spectroscopy measurements provide a depth profile of the $\mathrm{C}_{1 \mathrm{~s}}$ composition along the side chains. ${ }^{5-8}$ The wide energy distribution of the $C_{1 s}$ peak makes it possible to fit these peaks and quantitatively investigate the composition. The diblock copolymers form a bilayer structure with $R_{\mathrm{f}}$ groups segregated to the thin film surface. The PFA- $\mathrm{C}_{8}$ segregates to the outermost layer because the PFA-C 8 blocks have lower surface-free energy than do the PEG blocks. The PEG blocks are organized below the PFA- $\mathrm{C}_{8}$ layer. In this work, we investigated the chemical composition of the outermost surface using energy-resolved (ER) XPS. Diblock copolymers containing PEG and $\mathrm{PFA}_{-} \mathrm{C}_{8}$ were prepared by atom transfer radical polymerization. The chemical composition of the thin film surfaces was studied using ER-XPS based on the SR soft X-ray source.

\section{EXPERIMENTAL PROCEDURE}

The PEG(x)/PFA-C 8 (y) diblock copolymers were synthesized using a two-step procedure (Scheme 1). First, bromo-terminated PEG was prepared according to a previously reported method. ${ }^{9}$ The number-average molecular weight $\left(M_{\mathrm{n}}\right)$ of the monohydroxyl-functional PEG was $20000 \mathrm{~g} \mathrm{~mol}^{-1}$. Second, perfluorooctylethyl arylate $\left(\mathrm{FA}-\mathrm{C}_{8}\right)$ was polymerized from the bromo-terminated PEG macroinitiator using atom transfer radical polymerization. The polymerization was conducted using a tris[2-(dimethylamino)ethyl] amine $\left(\mathrm{Me}_{6} \mathrm{TREN}\right) / \mathrm{CuBr}$ catalyst system in hexafluoro-2-propanol at $325 \mathrm{~K}$. The ${ }^{1} \mathrm{H}$ NMR spectra of the PEG/PFA-C 8 diblock copolymers were measured with a BRUKER AV ANCE-III 400 using tetramethylsilane as an internal standard in $1: 1 \mathrm{CDCl}_{3} / \mathrm{AK}-225$ (a mixture of 1,1-dichloro-2,2,3,3,3-pentafluoropropane and 1,3-dichloro-1,1,2,2,3-pentafluoropropane, Asahi Glass, Tokyo, Japan). The $M_{\mathrm{n}}$ and volume fraction were determined by integrating the ${ }^{1} \mathrm{H}$ NMR signals (Supplementary Figure S1). The polydispersity index, $M_{\mathrm{w}} / M_{\mathrm{n}}$, was determined by size-exclusion chromatography using a Waters 1515 HPLC system (Waters, Milford, MA, USA) connected to three columns (Tosoh Bioscience, Tokyo, Japan) and equipped with a refractive index detector (Waters 2414, tungsten lamp); measurements were carried out at a rate of $0.5 \mathrm{ml} \mathrm{min}^{-1}$ at $313 \mathrm{~K}$ using hexafluoro-2-propanol as an eluent (Supplementary Figure S2). Differential scanning calorimetry measurements were performed using an EXSTAR6000 (Seiko Instruments Industries, Chiba, Japan) in a temperature range of $173-473 \mathrm{~K}$, at a heating rate of $10 \mathrm{~K} \mathrm{~min}^{-1}$ and under dry $\mathrm{N}_{2}$ gas. The $M_{\mathrm{n}}, M_{\mathrm{w}} / M_{\mathrm{n}}$ and melting temperature of the PEG/PFA- $\mathrm{C}_{8}$ diblock copolymers are listed in Table 1. XPS was carried out using a monochromatic $\mathrm{Mg} \mathrm{K} \alpha \mathrm{X}$-ray source of $1253.6 \mathrm{eV}$ and an SR soft X-ray source of $400 \mathrm{eV}$ on a BL12 beamline belonging to the Kyushu Synchrotron Light Research Center. We measured the survey scans and the high-resolution $\mathrm{C}_{1 \mathrm{~s}}$ XPS at a photoelectron take-off angle of $54^{\circ}$. The PEG(34)/ PFA- $\mathrm{C}_{8}(66)$ diblock copolymer thin films for XPS measurement were prepared by spin-coating at 2000 r.p.m. and were then annealed under reduced pressure at $343 \mathrm{~K}$ for $10 \mathrm{~h}$ and then quenched to room temperature. The thicknesses of the spin-coated films were approximately $20 \mathrm{~nm}$, as determined by atomic force microscopy (AFM) scanning on the scratched surfaces.

\section{RESULTS AND DISCUSSION}

Differential scanning calorimetry thermograms of the PEG(34)/PFA- $\mathrm{C}_{8}(66)$ diblock copolymer are shown in Figure 1. Two melting endothermic peaks can clearly be observed, which indicates that the PEG and 


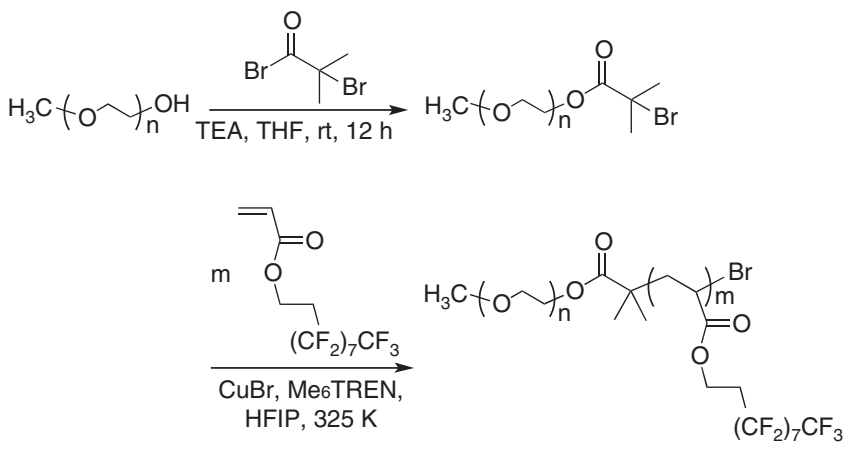

Scheme 1 Synthesis of PEG/PFA-C 8 diblock copolymers by atom transfer radical polymerization of FA$\mathrm{C}_{8}$ with a PEG macroinitiator. PEG, poly(ethylene glycol); PFA- $\mathrm{C}_{8}$, poly(perfluorooctylethyl acrylate).

Table 1 Characterization data of the synthesized poly(ethylene glycol) (PEG)/ poly(perfluorooctylethyl acrylate) (PFA- $\mathrm{C}_{8}$ ) diblock copolymers

\begin{tabular}{lcccccc}
\hline Copolymer & $F A-C_{8} / P E G^{\mathrm{a}}$ & $M_{n}^{\mathrm{b}}(\mathrm{kDa})$ & $M_{w} / M_{n}{ }^{\mathrm{c}}$ & $f_{P F A-C 8}(\mathrm{vol} \%)$ & $T_{m, P E G}{ }^{\mathrm{d}}(K)$ & $T_{m, P F A-C 8}{ }^{\mathrm{e}}(K)$ \\
\hline PEG(44)/PFA-C 8 (56) & 152 & 58.3 & 1.39 & 56 & 333 & 348 \\
PEG(34)/PFA-C 8 (66) & 152 & 78.9 & 1.33 & 66 & 333 & 349 \\
\hline
\end{tabular}

${ }^{a}$ Molar ratio of $\mathrm{FA}-\mathrm{C}_{8}$ monomer/PEG macroinitiator

${ }^{b}$ Number-average molecular weight determined by ${ }^{1} \mathrm{H}$ NMR $\left(\mathrm{CDCl}_{3} / \mathrm{AK}-225=50 / 50(\mathrm{vol} / \mathrm{vol})\right)$

CPolydispersity index determined by size-exclusion chromatography (hexafluoro-2-propanol, poly(methyl methacrylate) (PMMA) standards).

dMelting temperature of the PEG block determined by differential scanning calorimetry (DSC) measurement.

eMelting temperature of the PFA-C 8 block determined by DSC measurement.

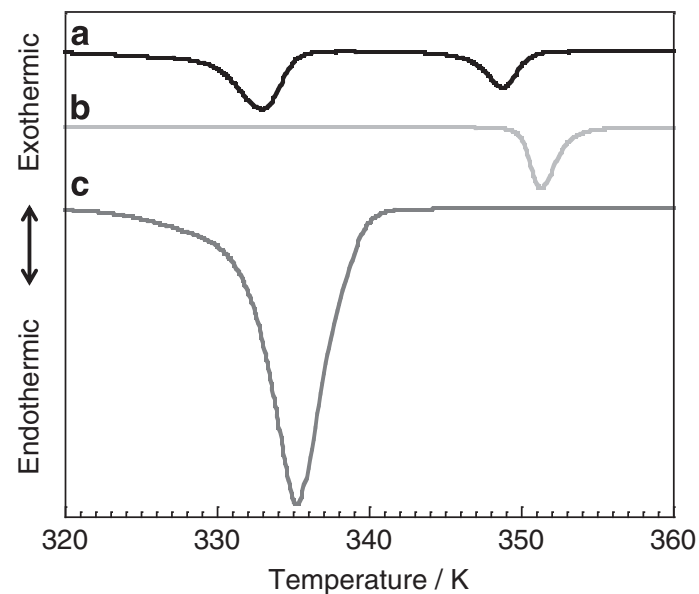

Figure 1 Differential scanning calorimetry thermograms of (a) PEG(34)/PFA-C 8 (66) diblock copolymer, (b) PFA-C 8 homopolymer and (c) PEG macroinitiator during the heating process at $10 \mathrm{~K} \mathrm{~min}^{-1}$. PEG, poly(ethylene glycol); $\mathrm{PFA}-\mathrm{C}_{8}$, poly(perfluorooctylethyl acrylate). A full color version of this figure is available at Polymer Journal online.

PFA- $\mathrm{C}_{8}$ blocks form a phase-separated structure with segregated PEG and $\mathrm{PFA}-\mathrm{C}_{8}$ phases. The melting temperatures of the PEG and PFA-C $\mathrm{C}_{8}$ crystalline domains are 333 and $349 \mathrm{~K}$, respectively. These melting temperatures are lower than those of the PEG macroinitiator and the PFA- $\mathrm{C}_{8}$ homopolymer. The enthalpy of fusion $\left(\Delta H_{\mathrm{m}}\right)$ of the

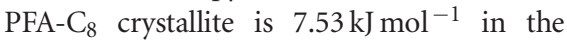
diblock copolymer, which is nearly equal to the $\Delta H_{\mathrm{m}}$ of the PFA- $\mathrm{C}_{8}$ homopolymer $\left(7.72 \mathrm{~kJ} \mathrm{~mol}^{-1}\right)$. The enthalpy of fusion of the PEG crystallite in the diblock copolymer, $4.95 \mathrm{~kJ} \mathrm{~mol}^{-1}$, is much smaller than for the PEG macroinitiator, $7.35 \mathrm{~kJ} \mathrm{~mol}^{-1}$. In the case of the PFA- $\mathrm{C}_{8}$ block, the melting point reduction is attributed to the decrease in the crystal domain size. For the PEG block, the decrease observed in the melting temperature and $\Delta H_{\mathrm{m}}$ suggests that crystallization is greatly suppressed by the confinement of the crystallized $\mathrm{PFA}-\mathrm{C}_{8}$ phase, which crystallizes at a higher temperature than does PEG. The confined geometry of the PEG phase inhibits lamellar growth, which results in a decrease in crystallite size and crystalline perfection and thereby depresses the melting temperature of the PEG phase. The XPS survey scan indicates that the $\mathrm{F} / \mathrm{C}$ ratio of the PEG(34)/PFA-C $\mathrm{C}_{8}(66)$ diblock copolymer thin film is 1.33 , which corresponds to the predicted $\mathrm{FA}_{-} \mathrm{C}_{8} \quad \mathrm{~F} / \mathrm{C}$ ratio of 1.31 (Supplementary Figure S3). The results show that the thin film surface is covered with PFA- $\mathrm{C}_{8}$ and that the perfluorooctyl groups are segregated to the outermost surface. The slight increase in $\mathrm{F} / \mathrm{C}$ ratio suggests that there is an excess of $-\left(\mathrm{CF}_{2}\right)_{7} \mathrm{CF}_{3}$ side groups at the outermost layer, which has a theoretical F/C ratio of 2.13. The surface segregation of fluorine-based species is well known and occurs due to the minimization of overall surface-free energy. The high-resolution XPS $\mathrm{C}_{1 \mathrm{~s}}$ spectra and peak deconvolution fittings of the PEG(34)/PFA- $\mathrm{C}_{8}(66)$ diblock copolymer thin films with the $\mathrm{Mg} \mathrm{K} \alpha \mathrm{X}$-ray and SR soft X-ray sources are shown in Figure 2. Shirley background correction and Gaussian/ Lorentzian peak fitting (50/50 ratio) were used for the peak deconvolution. All fitted peaks were constrained to have the same full width at half maximum. The measurements from the SR soft X-ray source show a larger $\mathrm{CF}_{3}$ peak area and smaller $\mathrm{C}-\mathrm{O}$ and hydrocarbon peak areas than the measurements obtained from the $\mathrm{Mg} \mathrm{K} \alpha \mathrm{X}$-ray source. The XPS analytical depth was estimated as $3 \lambda \sin$ $\theta$, where $\lambda$ is the inelastic mean free path of the photoelectrons and $\theta$ is the photoelectron take-off angle. The inelastic mean free path was estimated by the equation ${ }^{10}$

$$
\lambda=\frac{49}{10^{-3} \cdot \rho \cdot(\mathrm{KE})^{2}}+\frac{0.11 \cdot(\mathrm{KE})^{0.5}}{10^{-3} \cdot \rho}
$$

where $\rho$ is the density of organic material $\left(\mathrm{kg} \mathrm{m}^{-3}\right)$ and $\mathrm{KE}$ is the photoelectron kinetic energy $(\mathrm{eV})$. The densities of the PEG block and PFA-C $\mathrm{C}_{8}$ block were estimated to be 1200 and $2200 \mathrm{~kg} \mathrm{~m}^{-3}$, respectively. ${ }^{11}$ The inelastic mean free path for the PFA-C $C_{1}$ photoelectrons ( $285 \mathrm{eV}$ binding energy) was calculated to be $1.56 \mathrm{~nm}$ for the $\mathrm{Mg} \mathrm{K} \alpha \mathrm{X}$-ray $(1253.6 \mathrm{eV})$ and $0.54 \mathrm{~nm}$ for the SR soft $\mathrm{X}$-ray $(400 \mathrm{eV})$. The analytical depth for the PFA- $\mathrm{C}_{8} \mathrm{C}_{1 \mathrm{~s}}$ photoelectrons was $3.78 \mathrm{~nm}$ for the $\mathrm{Mg} \mathrm{K} \alpha \mathrm{X}$-ray source and $1.31 \mathrm{~nm}$ for the SR soft X-ray source. The fraction of the peak area corresponding to fluorinated carbons $\left(-\mathrm{CF}_{2}-\right.$ and $-\mathrm{CF}_{3}$, in Figure 2$)$ was 0.56 for the $\mathrm{Mg} \mathrm{K} \alpha \mathrm{X}$-ray, which is lower than the theoretical value of $8 / 13=0.62$ for the $\mathrm{FA}-\mathrm{C}_{8}$ monomer. This result indicates that both the $R_{\mathrm{f}}$ groups of the PFA-C $\mathrm{C}_{8}$ at the outermost 

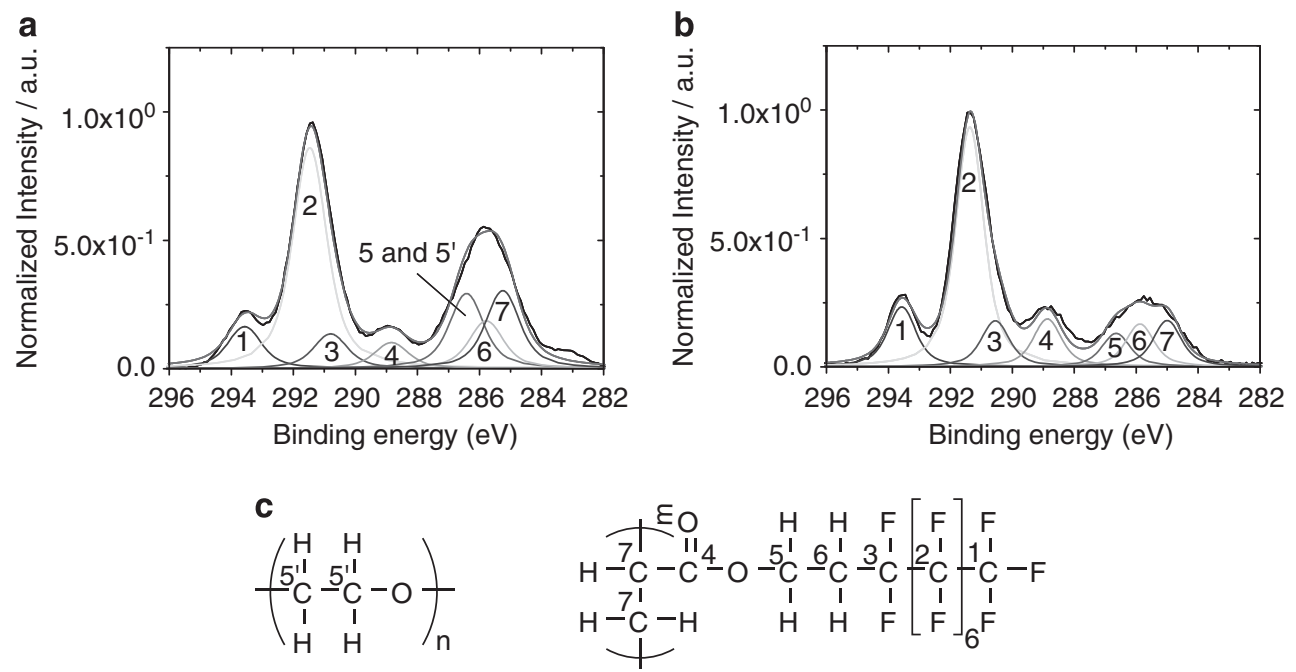

Figure 2 High-resolution $\mathrm{C}_{1 \mathrm{~s}}$ X-ray photoelectron spectroscopy spectra and peak deconvolution fittings of PEG(34)/PFA-C 8 (66) diblock copolymer thin films (a) with the $\mathrm{Mg} \mathrm{K \alpha}$ X-ray source $(1253.6 \mathrm{eV})$ and (b) with the synchrotron radiation soft $\mathrm{X}$-ray source $(400 \mathrm{eV})$. Peak assignments are shown in c. a.u., arbitrary unit; PEG, poly(ethylene glycol); PFA- $\mathrm{C}_{8}$, poly(perfluorooctylethyl acrylate). A full color version of this figure is available at Polymer Journal online.

surface and the PEG at the interior are within the XPS analytical depth for $\mathrm{Mg} \mathrm{K} \alpha \mathrm{X}$-ray source measurements. The single bilayer length of $\mathrm{PFA}^{-\mathrm{C}_{8}}$ was determined to be $\sim 3.3 \mathrm{~nm}$ by the grazing incidence $\mathrm{X}$-ray diffraction measurement, and the length of a fully extended $-\left(\mathrm{CF}_{2}\right)_{7} \mathrm{CF}_{3}$ chain in its helical conformation was $\sim 1.1 \mathrm{~nm}^{3,4,12,13}$ This length is shorter than the penetration depth of the $\mathrm{Mg} \mathrm{K} \alpha \mathrm{X}$-ray. Conversely, the fraction of the peak area corresponding to fluorinated carbons was 0.68 for the SR soft $\mathrm{X}$-ray, which is larger than the calculated value for the $\mathrm{FA}-\mathrm{C}_{8}$ monomer. This result indicates that the thin film surface is covered with PFA- $\mathrm{C}_{8}$ and that the measurements obtained using the SR soft X-ray source detected only the single bilayer of PFA- $\mathrm{C}_{8}$.

The $-\mathrm{CF}_{3} /\left(-\mathrm{CF}_{3}+-\mathrm{CF}_{2}-\right)$ peak area ratio was 0.15 for the $\mathrm{Mg} \mathrm{K \alpha} \mathrm{X-ray} \mathrm{and} 0.17$ for the SR soft X-ray. Both measurements gave a higher magnitude than the anticipated stoichiometric value of $1 / 8=0.125$, which shows that the $-\mathrm{CF}_{3}$ groups are segregated at the surface due to low surface-free energy. Given that XPS intensity decays exponentially with depth, this result confirms the proposed anisotropic orientation structure of the perfluorooctyl chains at the thin film surface. The fraction of peak area corresponding to ether carbons $(\mathrm{C}-\mathrm{O}$ peaks in Figure 2) was 0.091 for the $\mathrm{Mg} \mathrm{K} \alpha \mathrm{X}$-ray, which is higher than the theoretical value of $1 / 13=0.077$ calculated for the $\mathrm{FA}-\mathrm{C}_{8}$ monomer. This result also indicates that the PEG phase is within the XPS analytical depth for the $\mathrm{Mg}$ $\mathrm{K} \alpha \mathrm{X}$-ray source. The ether carbon fraction was 0.065 for the SR soft X-ray, which is lower than the theoretical value calculated for the $\mathrm{FA}-\mathrm{C}_{8}$ monomer. The photoelectrons from the $\mathrm{C}-\mathrm{O}$ carbon atoms are attenuated to a greater extent than are those from the fluorocarbon atoms because $\mathrm{C}-\mathrm{O}$ carbons are located deeper than the fluorocarbons, which are segregated to the surface. Grazing incidence X-ray diffraction and grazing incidence small-angle $\mathrm{X}$-ray scattering studies are currently underway to investigate the surface molecular aggregation states of the PEG/PFA$\mathrm{C}_{8}$ diblock copolymer thin film to confirm the accuracy of the $\mathrm{C}_{1 \mathrm{~s}}$ chemical analysis by ER-XPS.

\section{CONCLUSIONS}

We successfully prepared PEG/PFA-C 8 diblock copolymers by atom transfer radical polymerization of $\mathrm{FA}-\mathrm{C}_{8}$ with a PEG macroinitiator, and the outermost chemical composition of the thin film was evaluated by ER-XPS using an SR soft X-ray source. The ER-XPS deconvolution peak fitting demonstrates that the PEG/PFA- $\mathrm{C}_{8}$ diblock copolymer thin films build lamellar structure at the surface with $R_{\mathrm{f}}$ groups oriented perpendicular to the substrate. ER-XPS with an SR soft $\mathrm{X}$-ray source is a powerful tool for the chemical analysis of the outermost region of polymer thin films.

\section{ACKNOWLEDGEMENTS}

The synchrotron radiation experiments were performed using a BL12 beamline at Kyushu Synchrotron Light Research Center (Proposal No. 1303014S). This work was supported by the Photon and Quantum Basic Research Coordinated Development Program from the Ministry of
Education, Culture, Sports, Science and Technology, Japan. We appreciate Dr Kevin White's assistance with English writing. We gratefully acknowledge Dr Masamichi Morita (Daikin Industries Ltd) for the generous gift of FA- $\mathrm{C}_{8}$ monomer.

Shiki Nojima $^{1}$, Takamichi Shinohara ${ }^{1,2}$, Yuji Higaki ${ }^{1,2,3,4}$, Ryohei Ishige ${ }^{3}$, Tomoyuki Ohishi ${ }^{3}$, Daigo Kobayashi ${ }^{1}$, Hiroyuki Setoyama ${ }^{5}$ and Atsushi Takahara ${ }^{1,2,3,4}$

${ }^{1}$ Graduate School of Engineering, Kyushu University, Fukuoka, Japan;

${ }^{2}$ International Institute for Carbon-Neutral Energy Research (WPI-I2CNER), Kyushu University, Fukuoka, Japan;

${ }^{3}$ Institute for Materials Chemistry and Engineering, Kyushu University, Fukuoka, Japan; ${ }^{4} J a p a n$ Science and Technology Agency (JST), ERATO Takahara Soft Interface Project, Kyushu University, Fukuoka, Japan and ${ }^{5} \mathrm{Ky} u \mathrm{shu}$ Synchrotron Light Research Center, Saga, Japan

E-mail: takahara@cstf.kyushu-u.ac.jp

1 Beamson, G. \& Alexander, M. R. Angle-resolved XPS of fluorinated and semi-fluorinated side-chain polymers. Surf. Interface Anal. 36, 323-333 (2004).

2 Fadley, C. S., Baird, R. J., Siekhaus, W., Novakov, T. \& Bergstrom, S. A. L. Surface analysis and angular distributions in x-ray photoelectron spectroscopy. J. Electron Spectrosc. Relat. Phenom. 4, 93-137 (1974).

3 Volkov, V. V., Plate, N. A., Takahara, A., Kajiyama, T., Amaya, N. \& Murata, Y. Aggregation state and mesophase structure of comb-shaped polymers with fluorocarbon side group. Polymer (Guildf) 33 , 1316-1320 (1992). 
4 Honda, K., Yakabe, H., Koga, T., Sasaki, S. Sakata, O., Otsuka, H. \& Takahara, A. Molecular aggregation structure of poly(fluoroalkyl acrylate) thin films evaluated by synchrotron-sourced gazing incidence x-ray diffraction. Chem. Lett. 34, 1024 (2005).

5 Kim, J., Efimenko, K., Genzer, J. \& Carbonell, R. G. Surface properties of poly[2-(perfluorooctyl)ethyl acrylate] deposited from liquid $\mathrm{CO}_{2}$ high-pressure free meniscus coating. Macromolecules 40, 588-597 (2007).

6 Kassis, C. M., Steehler, J. K., Betts, D. E., Guan, Z., Romack, T. J., Desimone, J. M. \& Linton, R. W. XPS studies of fluorinated acrylate polymers and block copolymers with polystyrene. Macromolecules 29, 3247-3254 (1996)
7 Martinelli, E., Galli, G., Krishnan, S., Paik, M. Y., Ober C. K. \& Fischer, D. A. New poly(dimethylsiloxane)/ poly(perfluorooctylethyl acrylate) block copolymers: structure and order across multiple length scales in thin films. J. Mater. Chem. 21, 15357-15368 (2011).

8 Park, I. J., Lee, S. B., Choi, C. K. \& Kim, K. J. Surface properties and structure of poly (perfluoroalkylethyl methacrylate). J. Colloid Interface Sci. 181, 284-288 (1996).

9 Tian, Y., Watanabe, K., Kong, X., Abe, J. \& Iyoda, T. Synthesis, nanostructures, and functionality of amphiphilic liquid crystalline block copolymers with azobenzene moieties. Macromolecules 35, 3739-3747 (2002).

10 Roberts, R. F., Allara, D. L., Pryde, C. A., Buchanan, D. N. E. \& Hobbins, N. D. Mean free path for inelastic scattering of $1.2 \mathrm{kev}$ electrons in thin poly(methylmethacrylate) films. Surf. Interface Anal. 2 , 5 (1980).

11 Yamaguchi, H., Honda, K., Kobayashi, M., Morita, M. Masunaga, H., Sakata, O., Sasaki, S. \& Takahara, A Molecular aggregation state of surface-grafted poly\{2(perfluorooctyl)ethyl acrylate thin film analyzed by grazing incidence X-ray diffraction. Polym. J. 40, 864 (2008).

12 Corpart, J. M., Girault, S. \& Juhue, D. Structure and surface properties of liquid crystalline fluoroalkyl polyacrylates: role of the spacer. Langmuir 17, 7237-7244 (2001).

13 Viney, C., Russell, T. P., Depero, L. \& Twieg, R. J. Transitions to liquid crystalline phases in a semifluorinated alkane. Mol. Cryst. Liq. Cryst. 168, 63 (1989).

Supplementary Information accompanies the paper on Polymer Journal website (http://www.nature.com/pj) 